\title{
Management of lateral epicondylitis (tennis elbow) by local infiltration of platelet rich plasma an outcome study
}

\author{
Pradeep Kumar Kumawat ${ }^{1 *}$, Rajesh Goel ${ }^{2}$, Urmila Kumhar ${ }^{3}$, \\ Rajesh Sharma ${ }^{4}$, Rahul Parmar ${ }^{4}$, Bharat Sharma ${ }^{4}$
}

\author{
${ }^{1}$ Department of Orthopaedics, J. L. N. M. C., Ajmer, Rajasthan, India \\ ${ }^{2}$ Department of Orthopaedics, G. M. C., Kota, Rajasthan, India \\ ${ }^{3}$ M.Sc. (Medical) Microbiology, J. L. N. M. C., Ajmer, Rajasthan, India \\ ${ }^{4}$ Former Orthopedic Residents, G. M. C., Kota, Rajasthan, India
}

Received: 08 May 2020

Revised: 11 June 2020

Accepted: 16 June 2020

\section{*Correspondence:}

Dr. Pradeep Kumar Kumawat,

E-mail: pradeepkumawat832@gmail.com

Copyright: ( ) the author(s), publisher and licensee Medip Academy. This is an open-access article distributed under the terms of the Creative Commons Attribution Non-Commercial License, which permits unrestricted non-commercial use, distribution, and reproduction in any medium, provided the original work is properly cited.

\section{ABSTRACT}

Background: Platelet-rich plasma (PRP) has been recently the emerging biological therapy in which a large pool of signals released from platelets producing a biological microenvironment for local and migrating cells for tissue regeneration. A prospective randomized observational study was done to assess the efficacy of autologous PRP injection in lateral epicondylitis of elbow.

Methods: A total 100 patients of lateral epicondylitis were selected and treated from December 2015 to November 2017. VAS (visual analogue scale) and PRTEE (patient rated tennis elbow evaluation) scoring were used for clinical and functional assessment at pre-injection, $2^{\text {nd }}$ week, $4^{\text {th }}$ week, $3^{\text {rd }}$ month and $6^{\text {th }}$ month.

Results: At the end of 6 months follow-up $61 \%$ patients were completely relieved of pain. $34 \%$ patients had mild pain that was significantly decreased ( $p$ value $<0.0001$ ) from mean VAS (75) and mean PRTEE (78.62) to mean VAS (6.05) and mean PRTEE (5.63). 5 patients were lost their 6 months follow-up. There was a significant increase in post intervention pain for few days in $70 \%$ patients. Recurrence rate of $0 \%$ was noted at the end of 6 months follow-up.

Conclusions: An injection of PRP improves pain and function in patients suffering from lateral epicondylitis.

Keywords: Lateral epicondylitis, Platelet rich plasma injection, Visual analogue scale, Patient rated tennis elbow evaluation score

\section{INTRODUCTION}

Lateral epicondylitis is a common cause of lateral elbow pain that was first described by Runge. ${ }^{1}$ It is thought to represent an inflammation of the common extensor origin of the forearm and have a prevalence of $1.3 \%$ among those between 30 and 64 years of age, peaking between 45 and $54 .^{2}$ Mainly dominant upper limb is affected and associated with repeated forceful activity of limb.
Lateral epicondylitis, commonly known as "tennis elbow," occurs secondary to tendinosis of the extensor carpi radialis brevis origin immediately distal to the lateral epicondyle. The name is misleading because the lateral epicondyle is not the site of involvement, inflammation is not present, and most patients are not active tennis players.

Activities that require repeated contraction of the wrist extensors are responsible for tennis elbow like as lifting pots and pans or gripping a container of milk, wringing of washing clothes etc. Mainly extensor carpi radialis brevis 
(ECRB) tendon involved. Over time, the pain can become very severe and may compromise with routine activities. Lateral epicondylitis evolves through several stages, beginning with degenerative angiogenesis and ends with fibrosis and calcification. Lateral epicondyle demonstrates angio fibroblastic hyperplasia at the extensor origin of the forearm. ${ }^{3}$

Various nonsurgical methods have been advocated for treating elbow tendinosis, including rest, nonsteroidal antiinflammatory medication, bracing, physical therapy, iontophoresis, extracorporeal shock wave therapy, botulinum toxin and corticosteroid injection.

Platelet-rich plasma (PRP) has been recently the emerging biological therapy in which a large pool of signals released from platelets producing an instructional biological microenvironment for local and migrating cells for tissue regeneration. PRP modulate inflammation and angiogenesis largely because of their ability to secrete high levels of growth factors and chemokines. ${ }^{4}$ PRP injection for musculoskeletal injuries have advantage over other method of treatment in relation to have no risk of an anaphylactic reaction, no blood-borne transmitted infection, low cost, safety ,shorter recovery time compared to surgical management and availability for outpatient preparation and delivery.

The objectives of present study were; to determine demographic distribution of patient with lateral epicondylitis (tennis elbow), to study effect and functional outcome of lateral epicondylitis treated with PRP Infiltration at local site.

\section{METHODS}

This prospective randomized observational study was conducted in the department of orthopaedic, Govt. Medical College and associated group of hospitals, Kota between December 2015 to November 2017 after approval by ethical committee. 100 consecutive patients with lateral epicondylitis of the elbow were selected for the study

\section{Inclusion criteria}

A minimum age of 18 years and positive findings from two of the following clinical tests: cozen, mill, Gardner and Maudsley, tendinopathy present in lateral elbow, patients who had failed conservative treatment, symptoms lasting at least 3 months or longer, commitment to comply with all study procedures and the patient must give written informed consent were included in this study.

\section{Exclusion criteria}

Presence of full tendon tear with history of trauma, systemic autoimmune rheumatologic disease (connective tissue diseases and systemic necrotizing vasculitis), diabetes mellitus patient, blood disorders (thrombopathy, thrombocytopenia, anemia with $\mathrm{Hb}<9$ ), patient receiving immunosuppressive treatment, received local steroid injection within 3 months of randomization, received nonsteroidal anti-inflammatory, opioids, or oral corticosteroids within 15 days before inclusion in the study, severe heart disease, patients unable to comply with scheduled visits, patients with active cancer or cancer diagnosed, patient of hepatitis B, C, or HIV infection, pregnant or lactating women, other causes of elbow pain such as osteochondritis dissecans of capitellum, Varus instability, radial head arthritis, posterior interosseous nerve syndrome, synovitis of radio humeral joint, cervical radiculopathy, osteoarthritis of elbow patients were excluded from this study.

\section{Method of PRP preparation and infiltration}

PRP is derived from the centrifugation of autologous blood. $10 \mathrm{ml}$ autologous peripheral venous blood was collected from cubital vein of unaffected upper limb of patient and $9 \mathrm{ml}$ transferred into $1 \mathrm{ml} \mathrm{CDP}-\mathrm{A}$ (citric acid, sodium citrate, dextrose, monobasic sodium phosphate, adenine) containing sterile test tube. Rest $1 \mathrm{ml}$ was sent for complete blood count. Sample was processed through two staged centrifugations (first with $1600 \mathrm{rpm}$ for 10 minutes for separation of RBC and next with $3200 \mathrm{rpm}$ for 7 minutes in order to concentrate platelets). Final product was 1-1.5 $\mathrm{ml}$ PRP containing WBCs. The PRP quantification was performed using Automated Sysmex analyzer and if approved, the injection was proceeded.

\section{PRP infiltration}

With patient in supine posture, the bony anatomical landmarks were identified. The elbow was flexed to $90^{\circ}$ with the palm facing down. With proper aseptic precautions 1-1.5 ml PRP infiltrated using peppering technique just anterior and below the lateral epicondyle humerus.

\section{Outcome measures}

The clinical outcome was rated on the basis of VAS scale and PRTEE scoring system at every follow up. VAS pain scale: no pain (0-4 $\mathrm{mm})$, mild pain (5-44 mm) - pain present occasionally while at work, moderate pain (45-74 $\mathrm{mm}$ ) - pain present but can continue with work, severe pain (75-100 mm) - pain forces discontinuation of the work but can be resumed after rest. ${ }^{5}$

\section{PRTEE (patient-rated tennis elbow evaluation)}

Scoring system for both pain and functional disability. total score $=$ pain subscale + function subscale best score $=$ 0 worst score $=100 .^{6}$

\section{RESULTS}

Mean age of patients was $43.07 \pm 6.73$ (30-50) years. Mostly were house workers (57\%), laboure's (18\%), farmers (10\%) and others (15\%) including tailors, 
teachers, and drummers. Other patient's characteristics are shown in Table 1. In this study the mean VAS score and mean PRTEE score before injection were 75 (SD-5.99) and 78.62 (SD-4.68) respectively.

Table 1: Demographic characteristics.

\begin{tabular}{|c|c|c|}
\hline \multicolumn{3}{|c|}{ Demographic characteristics } \\
\hline Sex & Male $35(35 \%)$ & Female $65(65 \%)$ \\
\hline Mean age & 43.07 years \pm 6.73 & \\
\hline $\begin{array}{l}\text { Side of } \\
\text { involvement }\end{array}$ & Left $15(15 \%)$ & Right $85(85 \%)$ \\
\hline Dominance & $\begin{array}{l}\text { Dominant side } \\
\text { involved } 90(90 \%)\end{array}$ & $\begin{array}{l}\text { Non-dominant } \\
\text { side involved } 10 \\
(10 \%)\end{array}$ \\
\hline
\end{tabular}

At 2 weeks follow up, statistically significant difference in VAS scoring and PRTEE was seen. Mean VAS score was 55.25 (SD-7.50) and mean PRTEE score was 58.92 (SD8.52 ), showed statistically significant decrease in VAS score and PRTEE.

At $4^{\text {th }}$ week follow-up, there was statistically significant decrease in VAS score and PRTEE score. Mean VAS score was 40.25 (SD-8.31) and mean PRTEE score was 32.77 (SD-7.99).

At 3 months follow-up, mean VAS score was 19.25 (SD13.47) and mean PRTEE score was 16.35 (SD-9.43), showed statistically significant decrease in VAS score and PRTEE. 15 patients $(15 \%)$ were completely free from pain VAS score was 0. PRTEE score was 0 in $10(10 \%)$ patients.

Table 2: Mean VAS scoring.

\begin{tabular}{|c|c|c|c|c|c|}
\hline & Pre-injection VAS & 2 weeks VAS & $4^{\text {th }}$ weeks VAS & $3^{\text {rd }}$ months VAS & $6^{\text {th }}$ months VAS \\
\hline Mean VAS & 75 & 55.25 & 40.25 & 19.25 & 6.05 \\
\hline SD & 5.99 & 7.50 & 8.31 & 13.47 & 7.89 \\
\hline P value & $<0.0001$ & $<0.0001$ & $<0.0001$ & $<0.0001$ & $<0.0001$ \\
\hline
\end{tabular}

Table 3: Mean PRTEE score.

\begin{tabular}{|llllll|}
\hline & $\begin{array}{l}\text { Pre-injection } \\
\text { PRTEE }\end{array}$ & 2 weeks PRTEE & $\begin{array}{l}4^{\text {th }} \text { weeks } \\
\text { PRTEE }\end{array}$ & $\begin{array}{l}3^{\text {rd }} \text { months } \\
\text { PRTEE }\end{array}$ & $\begin{array}{l}\text { (th }^{\text {th }} \text { months }^{\text {PRTEE }} \\
\text { PRTEE }\end{array}$ \\
\hline $\begin{array}{l}\text { Mean PRTEE } \\
\text { score }\end{array}$ & 78.62 & 58.92 & 32.77 & 16.35 & 5.63 \\
\hline SD & 4.68 & 8.52 & 7.99 & 9.43 & 7.51 \\
\hline P value & $<0.0001$ & $<0.0001$ & $<0.0001$ & $<0.0001$ & $<0.0001$ \\
\hline
\end{tabular}

At the end of 6 months, 61 patients (61\%) were completely relieved of pain and functional disability. 34 patients $(34 \%)$ have mild pain mean VAS and PRTEE score were 6.05 and 5.63 respectively. 5 patients follow-up were lost at 6 months. No recurrence of pain and functional disability was seen. It was seen that there was a significant increase in post intervention pain for few days, 70 participants $(70 \%)$ complained of increase of pain after local infiltration that was treated with rest and ice fomentation for few days.

In this study mean platelet concentration in $\mathrm{CBC}$ was $241.25 \times 10^{3} / \mu 1$ and in PRP was $808.03 \times 10^{3} / \mu 1$ that was approximate 3-4 times to mean platelet concentration in CBC. It was seen that 80 patients $(80 \%)$ received 3 PRP injection, 2 injections were given in 20 patients (20\%). Maximum benefit was also seen after 3 injections. single injection was not given in any patient.

\section{DISCUSSION}

Platelet-rich plasma (PRP) is a volume of plasma fraction of autologous blood having platelet concentrations above baseline. The platelet $\alpha$ granules are rich in growth factors that play an essential role in tissue healing, such as transforming growth factor- $\beta$, vascular endothelial growth factor, and platelet-derived growth factor.

The properties of PRP are based on the production and release of multiple growth and differentiation factors when the platelets are activated. Platelets begin actively secreting these proteins within ten minutes of clotting, with more than $95 \%$ of the pre-synthesized growth factors secreted within one hour. ${ }^{7}$ After the initial burst of growth factors, the platelets synthesize and secrete additional such factors for the remaining several days of their life span. ${ }^{8}$

The combined action of all these growth factors is complex, and each may have a different effect on a particular tissue. Growth factors may also interact with each other, activating different sets of signaling pathways. Different isoforms of growth factors have varying effects that may enhance or inhibit osseous and soft-tissue repair, depending on the mode of release of the factor and the dynamics of the wound environment. ${ }^{9}$ 
Medical literature has sufficient studies to prove definitive role of PRP (platelet rich plasma) in healing of injured tissue. Cellular response to injury progresses through four general stages: hemostasis, inflammation, proliferation and finally remodeling. Each phase is characterized by enhanced cellular or Molecular activity, all of which involve platelets. Activated platelets and leucocytes mediate inflammation while various growth factors derived from platelets alfa granules influence tissue regeneration. Specifically, angiogenic and mitogenic growth factor concentrations are believed to aid tissue regeneration. ${ }^{10}$

In this current study, the mean age encountered was 43 years (Range: 30 to 56 years); the peak incidence was seen from 30 to 50 years. Similar observation (mean age 45 \pm 5.9 years) was seen in Raeissadat et al. ${ }^{11}$

In this current study, out of the 100 participants, 65 (65\%) were female patients and $35(35 \%)$ were male patients. Near similar observation (male $37 \%$ and female $63 \%$ ) seen in study Omar et al and (male $40 \%$ and female 60\%) in Raeissadat et al. ${ }^{8,12}$ More number of female patients in this current study may be due to that, females were more involved with household work which causes repetitive stress at the extensor carpi radialis brevis origin causing micro trauma, a relevant etiology for the initiation of the disease.

In this current study, out of the 100 participants, 85 (85\%) participants had their right-side elbow affected and 15 $(15 \%)$ had their left side affected. Out of the 100 participants, 90 (90\%) participants had their Dominant elbow affected and $10(10 \%)$ had their Non dominant elbow affected. In other two studies, one had $86 \%$ of the patients with their dominant elbow affected, while in another $80 \%$ of the patients with their dominant side affected. $^{13,14}$ Parameters like age, sex, side of elbow involved, dominance of upper limb involved were comparable.

In this study the mean VAS score and PRTEE score before injection were comparable. Mean VAS score was 75 (SD5.99) and mean PRTEE score was 79.52 (SD-5.56) Raeissadat et al. ${ }^{11}$ At 2 weeks follow-up, statistically significant ( $\mathrm{p}$ value $<0.0001$ ) difference in VAS scoring and PRTEE was seen. Mean VAS score was 55.25 (SD7.50) which was comparable with a study (Gautam et al). ${ }^{15}$ Mean PRTEE score was 58.92 (SD-8.52).

At $4^{\text {th }}$ week follow-up, there was statistically significant ( $p$ value $<0.0001$ ) decrease in VAS score and PRTEE score. Mean VAS score was 40.25 (SD-8.31) which was comparable $(41.7 \pm 2.2)$ with a study Raeissadat et al. ${ }^{11}$ Mean PRTEE score was 32.77 (SD-7.99).

At 3 months follow-up, mean VAS score was 19.25 (SD13.47) which was comparable $(18 \pm 6)$ with a study (VK Gautam et al). ${ }^{15}$ Mean VAS was 16 in Yadav et al and mean PRTEE score was 16.35 (SD-9.43) comparable (mean PRTEE-13) with Palacio et al, showed statistically significant ( $\mathrm{p}$ value $<0.0001$ ) decrease in VAS score and PRTEE. ${ }^{16,17} 15$ patients (15\%) were completely free from pain, VAS score was 0 . PRTEE score was 0 in $10(10 \%)$ patients. At the end of 6 months there was no recurrence.

At the end of 6 months, 61 patients $(61 \%)$ were completely relieved of pain and functional disability. 34 patients (34\%) have mild pain. Mean VAS and PRTEE score were 6.05 and 5.63 respectively showed statistically significant ( $\mathrm{p}$ value $<0.0001$ ). 5 patients follow-up were lost at 6 months. It was seen that there was a significant increase in post intervention pain for few days, 70 participants (70\%) complained of increase of pain after local infiltration. This was also seen in other PRP studies Peerboom et al, Krogh et al. ${ }^{14,18}$

In this current study it was seen that mean platelet concentration in whole blood was about $241.25 \times 10^{3} / \mu \mathrm{l}$ (SD-58.01) and mean platelet concentration in PRP was about $808.03 \times 10^{3} / \mu \mathrm{l}$ (SD-138.82) that is average 3-4 folds increase in platelet concentration over baseline. Another study had shown that clinical efficacy can be expected with a minimum increase in platelet concentration of 4 to 6 folds from whole blood baseline $\left(200 \times 10^{3}\right.$ platelets $\left./ \mu \mathrm{l}\right) .{ }^{19}$ In this study the number of mean PRP injection was 2.8 (approximate 3).

\section{CONCLUSION}

Platelet rich plasma injection technique for lateral epicondylitis offers a better treatment with these advantages; (1) its application is minimally traumatic, (2) it has a reduced risk for immune- mediated reactionsanaphylaxis, devoid of potential complications such as hypoglycemia, skin atrophy, tendon tears associated with corticosteroid injection, (3) it is simple to acquire and prepare, easy to carry out as outpatient procedure and (4) it is inexpensive (5) better relief of pain, (6) low recurrence rate.

\section{Funding: No funding sources \\ Conflict of interest: None declared}

Ethical approval: The study was approved by the institutional ethics committee

\section{REFERENCES}

1. Runge F. For the genesis and treatment of the writing crane. Bed Klin Worchenschr. 1873;10:245-24.

2. Shiri R, Viikari-Juntura E, Varonen H, Heliövaara M. Prevalence and determinants of lateral and medial epicondylitis: a population study. Am J Epidemiol. 2006;164(11):1065-74.

3. Regan W, Wold LE, Coonrad R, Morrey BF. Microscopic histopathology of chronic refractory lateral epicondylitis. Am J Sports Med. 1992;20(6):746-9. 
4. Andia I, Abate M. Platelet rich plasma injections for tendinopathy and osteoarthritis. Int $\mathbf{J}$ Clin Rheumatol. 2012;7:397-412.

5. Aun C, Lam YM, Collect B. Evaluation of the use of visual analogue scale in Chinese patients. Pain. 1986;25:215-21.

6. MacDermid JC. The Patient-Rated Tennis Elbow Evaluation (PRTEE) User Manual. Hamilton, Canada: School of Rehabilitation Science, McMaster University. 2007. Available at: https://srsmcmaster.ca/wp-content/uploads/2015/05/EnglishPRTEE-User-Manual_June-2010.pdf. Accessed on $12^{\text {th }}$ April 2020.

7. Marx RE. Platelet-rich plasma (PRP): what is PRP and what is not PRP? Implant Dent. 2001;10:225-8.

8. Marx RE. Platelet-rich plasma: evidence to support its use. J Oral Maxillofac Surg. 2004;62:498-93.

9. Bucholz RW, Einhorn TA, Marsh JL. Bone and joint healing. In: Bucholz RW, Heckman JD, CourtBrown C, eds. Rockwood and Green's fractures in adults. Sixth ed. Lippincott Williams and Wilkins; 2006:300-11.

10. Anitua E, Andia I, Ardanza B, Nurden P, Nurden AT. Autologous platelets as a source of proteins for healing and tissue regeneration. Thromb Haemost. 2004;91:4-15.

11. Raeissadat SA, Rayegani SM, Hassanabadi H, Rahimi R, Sedighipour L, Rostami K. Is platelet-rich plasma superior to whole blood in the management of chronic tennis elbow: one year randomized clinical trial. BMC Sports Science, Med Rehab. 2014;6(1):12.

12. Omar Aziza S, Maha EI, Amal SA, Mahmoud S. Local injection of autologous platelet rich plasma and corticosteroid in treatment of lateral epicondylitis and plantar fasciitis: randomized clinical trial. Egypt Rheumatol. 2012;34:43-9.

13. Thanasas C, Papadimitriou G, Charalambidis C, Paraskevopoulos I, Papanikolaou A. Platelet-rich plasma versus autologous whole blood for the treatment of chronic lateral elbow epicondylitis: a randomized controlled clinical trial. Am J Sports Med. 2011;39:2130-4.

14. Krogh TP, Fredberg U, Stengaard-Pedersen K, Christensen R, Jensen P, Ellingsen T. Treatment of lateral epicondylitis with platelet-rich plasma, glucocorticoid, or saline: a randomized, doubleblind, placebo-controlled trial. Am J Sports Med. 2013;41:625-35.

15. Gautam VK, Verma S, Batra S, Bhatnagar N, Arora S. Platelet-rich plasma versus corticosteroid injection for recalcitrant lateral epicondylitis: clinical and ultrasonographic evaluation. J Orthopaed Surg. 2015;23(1):1-5.

16. Yadav R, Kothari SY, Borah D. Comparison of local injection of platelet rich plasma and corticosteroids in the treatment of lateral epicondylitis of humerus. $\mathbf{J}$ Clin Diagnos Res. 2015;9(7):RC05.

17. Palacio EP, Schiavetti RR, Kanematsu M, Ikeda TM, Mizobuchi RR, Galbiatti JA. Effects of platelet-rich plasma on lateral epicondylitis of the elbow: prospective randomized controlled trial. Rev Bras Ortop. 2016;51(1):90-5.

18. Peerbooms JC, Sluimer J, Bruijn DJ, Gosens T. Positive effect of an autologous platelet concentrate in lateral epicondylitis in a double-blind randomized controlled trial: platelet-rich plasma versus corticosteroid injection with a 1-year follow-up. Am J Sports Med. 2010;38:255-62.

19. Weibrich G, Kleis WKG, Hafner G, Hitzler WE. Growth factor levels in plateletrich plasma and correlations with donor age, sex, and platelet count. J Cranio Maxillofacial Surg. 2002;30:97-102.

Cite this article as: Kumawat PK, Goel R, Kumhar U, Sharma R, Parmar R, Sharma B. Management of lateral epicondylitis (tennis elbow) by local infiltration of platelet rich plasma an outcome study. Int J Res Orthop 2020;6:963-7. 